\title{
OFICINAS DE PRIMEIROS SOCORROS: relato de experiência
}

\author{
Andréa M árian VERONESE a , D ora Lúcia Leidens Corrêa de OLIVEIRA ${ }^{\text {, }}$ \\ I saquiel M acedo da ROSA ${ }^{c}, K^{2}$ aroline NAST ${ }^{d}$
}

\begin{abstract}
RESUMO
Este relato de experiência é resultado do processo de construção de oficinas de primeiros socorros, oferecidas aos moradores do bairro Cavalhada, da cidade de Porto Alegre, Rio Grande do Sul. As oficinas resultaram da preocupação dos pesquisadores, envol vidos no projeto "R isco de vida na perspectiva dos usuários do Serviço de A tendimento M óvel de U rgência de Porto A legre (SAM U ) - subsídios para a gestão do serviço", em interferir, de forma mais dinâmica, na real idade estudada. A o produzirmos este relato, buscamos fornecer subsídios para experiências no ensino de primeiros socorros.
\end{abstract}

Descritores: Primeiros socorros. E ducação em saúde. E nfermagem em emergência.

\section{RESUMEN}

E steinforme de experiencia es el resultado del proceso de construcción detalleres de primer os auxilios ofrecidos a los habitantes del bar rio Cavalhada de la ciudad de Porto A legre, R io G rande do Sul, B rasil. L os talleres resultaron de la preocupación de los investigadores, involucrados en el proyecto "R iesgo devida bajo la perspectiva de los usuarios del Servicio deA tención M óvil deU rgencia de Porto A legre (SAM U ) - informaciones para la gestión del servicio", en interferir de una forma más dinámica acerca de la realidad estudiada. E n la producción de este informe, buscamos proveer informaciones para experiencias en la enseñanza de primeros auxilios.

Descriptores: P rimeros auxilios. E ducación en salud. E nfermería de urgencia.

Título: T alleres de primeros auxilios: informe de una experiencia.

\section{ABSTRACT}

This experiencereport is the result of theconstruction process of w orkshops on first aid offered to inhabitants of Cavalhada, a neighborhood in P or to A legre, R io G rande do Sul, B razil. T hew orkshops resulted from a concern of researchers involved in the project "L ife risk under the perspective of users of the M obileU rgency Care Service of Porto Alegre (SAM U ) - in puts for the ser vice management". They ai med to interfere in the studied reality in a dynamic way. W ith this report, we intend to provide in puts for experiences in teaching first aid.

Descriptors: F irst aid. H ealth education. E mergency nursing.

Title: F irst aid workshop: report of an experience.

\footnotetext{
a M estre em Enfermagem, D outoranda em Enfermagem pelo Programa de Pós-G raduação em Enfermagem (PPFEnf) da U niversidade Federal do Rio Grande do Sul (U FRGS), Enfermeira do Serviço de Atendimento M óvel de U rgência (Samu), M embro do Grupo de Estudos em Promoção da Saúde (GEPS), Porto Alegre, Rio Grande do Sul, Brasil.

b PhD em Educação, Professora do PPFEnf/ UFRGS, Coordenadora do GEPS, Porto Alegre, Rio Grande do Sul, Brasil.

c E nfermeiro, M estrando em E nfermagem pelo P PG E nf/ U F RG S, Bolsista da Coordenação de A perfeiçoamento de Pessoal de N ível Superior (CAPES), M embro do GEPS, Porto Alegre, Rio Grande do Sul, Brasil.

d G raduanda em E nfermagem pela E scola de E nfermagem da U FRG S, Bolsista do Programa Institucional de Bolsa de I niciação Científica (PIBIC) do Consel ho N acional de Desenvolvimento Científico e Tecnológico CN PQ, M embro do GE PS, Porto Alegre, Rio G rande do Sul, Brasil.
} 


\section{INTRODUÇÃO}

A pesar de sua grande relevância, tendo em vista a quantidade de ag ravos à saúde que acontece, cotidianamente, no trânsito, nos domicílios, no ambiente de trabal ho e em outros locais, no Brasil, 0 ensino de primeiros socorros ainda é pouco difundido, prevalecendo o desconhecimento sobre 0 tema ${ }^{(1)}$.

D urante o desenvolvimento da pesquisa " $R$ isco de vida na perspectiva dos usuários do Serviço de A tendimento M óvel de U rgência (SAM U) de Porto A legre - subsídios para a gestão do serviço"e, surgiu entre os moradores da região de Porto Alegre onde o estudo foi realizado, uma forte demanda por conhecimentos de primeiros socorros. É preciso salientar que, desde a formulação do projeto de pesquisa, foi nossa preocupação, para além da produção de conhecimentos, oferecer um retorno mais imediato à população envolvida no trabalho de campo. Partimos do pressuposto de que é preciso socializar os saberes, produzidos na academia, seja no âmbito da pesquisa, ensino ou extensão, perante uma construção dialógica com a sociedade, para que ambas, universidade e população, compartilhem seus conhecimentos sobre primeiros socorros. Portanto, o interesse da população entrou em sintonia com a proposta, já incluída na agenda inicial da pesquisa, de realizar oficinas sobre primeiros socorros.

Nossa experiência, no ensino de primeiros socorros, ocorreu junto a um grupo de moradores do Bairro Caval hada da cidade de Porto Alegre, Rio Grande do Sul, e buscou ampliar os saberes e práticas que envolvem a referida atividade. A o produzirmos este relato de experiência, foi nossa intenção for necer subsídios para o desenvolvimento de iniciativas no ensino de primeiros socorros.

\section{CONST RUINDO AS OFICINAS DE PRIMEIROS SOCORROS}

No âmbito do SAM U de Porto Alegre, tal qual ocorre em serviços de atendimento pré-hospitalar móvel de outros países(2), é comum o recebimento de chamadas tel efônicas demandando o envio de ambulâncias para atendimento de situações que, embora aval iadas como urgentes pel os solicitantes,

e Projeto aprovado pelo Comitê de É tica em Pesquisa da Secretaria da Saúde de Porto Alegre, nํ 121.16/ 01/ 2007. são consider adas, pel o médico regulador, como não pertinentes à natureza do serviço, por não serem suficientemente graves para justificar o envio de uma ambulância. N essas situações, os médicos do SAM U orientam os solicitantes sobre procedimentos a serem realizados ou sobre a necessidade de encaminhamentos a outros serviços, confor me cada caso.

A partir da análise de demandas não pertinentes ao SAM U, do bairro Caval hada, no ano de 2006, foi possível identificar uma importante concentração dessa demanda em área onde se localizam loteamentos populares. Com o objetivo de apresentar a proposta das oficinas de primeiros socorros, uma das pesquisadoras passou a frequentar as reuniões da Rede de Proteção da Criança e do Adolescente das regiões Sul e Centro-Sul de Por to A leg re, onde se localiza o bairro Cavalhada. N essa rede se reúnem os representantes do ConseIho T utelar, das ár eas da educação, saúde e assistência social, entre outras, para a implementação de ações comunitárias conjuntas.

A proposta de realizar oficinas de primeiros socorros para a população que solicitava o SAM U para casos não graves tinha dois propósitos: atualizar conhecimentos sobre primeiros socorros e esclarecer os objetivos do trabal ho do SAM U. A proposta foi acolhida pelos participantes da rede, sendo disponibilizada a sede da $\mathrm{F}$ undação de Assistência Social e Cidadania (FASC) - Cavalhada para a realização do trabal ho educativo, pois grupos já constituídos na Fasc haviam demandado abordagens sobre saúde.

As oficinas foram planejadas de forma a atender a população do bairro e, em particular, as pessoas que participavam de grupos quinzenais nos programas assistenciais da Fasc: N úcleo de A poio Sócio Familiar (NASF) e programa de Proteção e Erradicação do Trabalho Infantil (PETI). Três grupos participaram das atividades, sendo realizados um total de sete encontros de três horas cada, com uma média de oito participantes, na maioria mulheres entre 20-40 anos. T ambém integraram as oficinas um assistente social e uma psicóloga que atuam na Fasc, além das duas facilitadorasf.

As oficinas versaram sobre: funcionamento do SAM U, obstrução de vias aéreas por corpo estranho, parada cardior respiratória, atendimento a fra-

\footnotetext{
${ }^{f}$ A primeira e a quarta autora desse artigo foram as facilitadoras das oficinas.
} 
turas, luxações, entorses, contusões e hemorragias, acidente vascular encefálico, parto, febre, convulsões, insuficiência respir atória eintoxicações. Os temas abordados foram propostos tanto pelas facilitadoras, quanto pelos participantes, reconhecendo-se a importância deste espaço para dar visibilidade às experiências de cada um. Seis momentos constituíram os encontros: apresentação dos participantes, exercício de reflexão sobre experiências vividas nas urgências a serem abordadas no encontro, atualização dos saberes que emergiam neste exercício com simulações de primeiros socorros, problematização das condições dos participantes para a realização dos atendimentos, retomada dos saberes aprendidos e aval iação qual itativa da atividade.

A orientação pedagógica utilizada nas oficinas foi a da problematização ${ }^{(3)}$. A realidade dos participantes, experiências, conhecimentos prévios, opiniões, dúvidas e estratégias utilizadas no dia-adia para atendimento de urgências, bem como as tomadas de decisão, que resultam em chamadas ao SAM U, foram discutidas de forma participativa. 0 material didático utilizado foi constituído de: cartazes; folhetos explicativos sobre cada assunto abordado; manequins próprios para o ensino de parada cardior respiratória; tal as improvisadas com travesseiros, papelões, madeira, tecidos, roupas, entre outros.

A orientação sobre a abordagem de situações de urgência e primeiros socor ros levou sempre em consideração as necessidades dos participantes e os recursos disponíveis, criando a oportunidade de uma aprendizagem singular, pois foi construída a partir das suas próprias experiências. Diferentemente das tradicionais palestras, em que 0 autoritarismo e a verticalidade do ato educativo estão presentes, as oficinas abriram espaços para o diálogo e a crítica sobre determinado cotidiano ${ }^{(4)}$. As facilitadoras assumiram um papel de coparticipante, 0 que favoreceu a construção compartilhada de conhecimentos ${ }^{(5)}$.

No decorrer dos encontros, surgiram diversas dúvidas, como o uso adequado do termômetro e a identificação de sinais vitais. Além disso, crenças populares também foram referidas, como, por exemplo, a de que rodelas de cebola crua sobre os pés das crianças, assim que murcham, indicam que a febre diminuiu ou cessou. N esse caso, tivemos o cuidado de não desqualificar o procedimento, que deve ter sido passado de geração em geração nas famílias, embora tenhamos enfatizado a importância e eficácia do termômetro quanto ao controle da temperatura corporal. Foi destacado que o uso da cebola não deve dispensar o uso do termômetro, visto que este é mais preciso, al ertando-se as mães para os perigos da falta de um controle rigoroso da temper atura e as possíveis consequências da febre alta. T ambém participaram do grupo, pessoas portadoras de asma ou seus familiares. O portunamente, uma das participantes contribuiu com a importante informação de que há, na comunidade, um grupo que se encontra periodicamente para discutir assuntos relativos à asma. Esse fato era, até então, desconhecido pel os outros participantes, bem como o número telefônico do Centro de Informações Toxicológicas, que foi devidamente divulgado. Por outro lado, emergiram questionamentos sobre gestação e parto, o que demonstra a necessidade de futuros trabal hos educativos voltados para estes temas.

Quanto ao trabal ho do SAM U, os participantes demonstraram conhecer os objetivos do serviço e os procedimentos para acessá-lo, informando que, além de ligar para solicitar atendimento de urgência, também recorrem ao serviço para transporte a pronto-atendimentos, o que sugere dificuldades de acesso a outros serviços de saúde.

\section{CONSIDERAÇÕES FINAIS}

0 ensino de primeiros socorros deveria ser amplamente disponibilizado e democratizado. Hoje, aprender sobre primeiros socorros é restrito aos profissionais de saúde ou àquel es que estão próximos de universidades, hospitais e de outros centros que promovem tais cursos. Além de conferir aos usuários maior segurança para tratar de seus problemas de saúde, reduzindo sua vul ner abilidade, a produção e social ização de conhecimentos sobre primeiros socorros pode gerar diminuição da demanda considerada não pertinente ao SAM U, tornando mais eficiente e otimizado 0 atendimento de urgências desse serviço.

A opção pela problematização, como abordagem metodológica das oficinas, conferiu dinamismo aos encontros e oportunidade de participação dos usuários no processo educativo, contrariando modelagens educativas mais tradicionais que trabal ham com a sel eção e exposição vertical de conteúdos por parte dos educadores. 0 diálogo possibilitou o compartilhamento de dúvidas referentes 
a primeir os socorros, as quais foram tratadas, sempre, de forma participativa, buscando-se a atualização dos conhecimentos ${ }^{(6)}$. E ssa troca pedagógica propiciada pelo diálogo foi importante para a aprendizagem, não só dos participantes, mas, também, das facilitadoras, ampliando o olhar para além da técnica, instigando a criatividade e ensinando novas formas de fazer construídas naquela cultura.

Quanto aos limites evidenciados na utilização das oficinas para abordar primeiros socorros, podemos citar a diferença entre uma simulação e a real idade vivida. As condições do ambiente, a disponibilidade de recursos e o clima emocional presente numa situação de urgência e risco de vida são fatores que não podem ser simulados de uma forma fidedigna. Além disto, seria importante desenvolver estas oficinas de forma continuada, sobretudo, nos serviços de atenção básica.

Finalmente, destacamos que a responsabilidade social dos pesquisadores é fator importante a ser considerado ${ }^{(7)}$. A exemplo das oficinas apontadas neste artigo é fundamental que, de maneira mais imediata, os pesquisadores devolvam aos cidadãos os resultados das suas pesquisas. Compartilhando os resultados de estudos com os pesquisadores, os cidadãos poderão, inclusive, julgar 0 mérito dos investimentos em pesquisas e em programas de pós-graduação. Os pesquisadores formados por programas sensíveis à necessidade de redução de vul nerabilidades e comprometidos com a promoção de melhores condições de vida da população saberão dar valor ao investimento que a sociedade faz nel es e serão por ela reconhecidos.

\section{REFERÊNCIAS}

1 Pergola M A, Araújo IE M . O leigo e o suporte básico de vida. Rev E sc E nferm U SP. 2009;43(2):335-42.
2 Kawakami C, Ohshige K, Kubota K, Tochikubo 0. Influence of socioeconomic factors on medically unnecessary ambulance calls. BM C H ealth Serv Res [ Internet] . 2007 [ cited 2008 Feb 18];7(120):1-9. Available from: http:/ / www.biomedcentral.com/ $1472-6963 / 7 / 120$.

3 F reire $P$. Pedagogia do oprimido. 42 a ed. Rio de Janeiro: Paz e Terra; 2005.

4 Souza AC, Colome ICS, Costa LED, Oliveira D LLC. A educação em saúde com grupos na comunidade: uma estratégia facilitadora da promoção da saúde. Rev $\mathrm{G}$ aúcha Enferm. 2005;26(2):147-53.

5 Corcione D. Fazendo oficina. In: M inistério da Saúde (BR ), Secretaria de G estão do T rabal ho e da E ducação na Saúde, D epartamento de G estão da E ducação. Rev-SU S Brasil: cadernos de textos. Brasília (DF); 2004. p. 30-35.

6 Freire P. Pedagogia da autonomia: saberes necessários à prática educativa. 31ª ed. São Paulo: Paz e T erra; 2005.

7 Dantas F. Responsabilidade social e pós-graduação no Brasil: idéias para (avali)ação. RBPG : Rev Bras Pós-Grad [Internet]. 2004 [ citado 2009 dez 10]; 1(2):160-72. Disponível em: http:/ / www2.capes.gov. $\mathrm{br} / \mathrm{rbpg} /$ index.php/ numeros-publicados/volume-1no2.

\section{AGRADECIMENTOS}

À F undação de A mparo à Pesquisa do E stado do Rio G rande do Sul (Fapergs) e M inistério da Saúde E dital PPSU SII - pel o financiamento da pesquisa "R isco de vida na perspectiva dos usuários do Serviço de A tendimento M óvel de U rgência (SA M U) de Porto Alegre - subsídios para a gestão do serviço".

\section{Endereço da autora / Dirección del autor / Author's address:}

Andréa M árian Veronese

Rua Comendador Castro, 140, I panema

91760-200, Porto Alegre, RS

E-mail: andreamv@terra.com.br
Recebido em: 05/ 01/ 2010

A provado em: 15/ 03/ 2010 